\title{
Actividades comerciales turísticas luego de filmar Bandidas y Spectre
}

\section{Tourist commercial activities after filming Bandidas and Spectre}

\author{
LÓPEZ-HERNÁNDEZ, Sonia*†, LÓPEZ-MARTÍNEZ, Ma. Teresa y ESQUIVEL, Rocío \\ Instituto de Ciencias de la Comunicación, Universidad del Mar, campus Huatulco, Oaxaca México.
}

ID $1^{\text {er }}$ Autor: Sonia, López-Hernández / ORC ID: 0000-0002-9669-1488, Researcher ID Thomson: S-6911-2018

ID $1^{\text {er }}$ Coautor: Ma. Teresa, López-Martínez / ORC ID: 0000-0001-6800-1833, Researcher ID Thomson: S-6907-2018

ID $2^{\text {do }}$ Coautor: Rocío, Esquivel / ORC ID: 0000-0003-4000-2732, Researcher ID Thomson: B-8710-2018, CVU CONACYT ID: 473897

DOI: $10.35429 / J T M S .2019 .15 .5 .15 .25$

Recibido 04 de Marzo 2019; Aceptado 30 Junio, 2019

\begin{abstract}
Resumen
En México los casos en los cuales se ha registrado y evidenciado un aumento de las actividades comerciales para el turismo tras una producción cinematográfica son escasos pese a que las producciones cinematográficas (considerando sus múltiples procesos publicidad, grabación y noticias) son un foro de configuración de espacios turísticos y parte una industria de distribución de contenidos culturales en crecimiento ideal para la promoción de destinos. Las diferentes locaciones de México en las que se filmaron Bandidas (2006) y Spectre (2015), han aprovechado de forma diferente el atractivo que representa figurar en una producción cinematográfica y muestran una planificación de servicios turísticos disímil. La metodología adoptada fue una combinación de técnicas (Arias Alpízar, 2009) (Hernández Sampieri, Fernandez Collado, \& Baptista Lucio, 2003). La parte cuantitativa se valió de la caracterización la zona, revisión de los catálogos de servicios turísticos de las regiones, comparación histórica de la evolución de los servicios turísticos relacionados con la filmación de las películas (Ander, 1989). Por otra parte, como parte cualitativa, se utilizó la entrevista (Hernández Sampieri, Fernandez Collado, \& Baptista Lucio, 2003) para que los involucrados en estos servicios externaran sus valoraciones de la temática. Asimismo se realizó una revisión hemerográfica digital (Ander, 1989) para conocer la promoción publicitaria de las regiones utilizando como atributo la filmación de las producciones cinematográficas en la zona.
\end{abstract}

Spectre, Bandidas, Actividades comerciales turísticas, Producciones cinematográficas y turismo

\begin{abstract}
In Mexico, the cases in which an increase in commercial activities for tourism following a film production have been recorded and evidenced are scarce, despite the fact that cinematographic productions (considering their multiple processes of advertising, recording and news) are a forum for the configuration of tourist areas and part an industry of distribution of cultural contents in growth ideal for the promotion of destinations. The different locations in Mexico in which Bandidas (2006) and Spectre (2015) were filmed, have made different use of the attraction of a film production and show a different tourism service planning. The methodology adopted was a combination of techniques (Arias Alpízar, 2009) (Hernández Sampieri, Fernández Collado, \& Baptista Lucio, 2003). The quantitative part made use of the characterization of the area, review of the catalogs of tourist services in the regions, historical comparison of the evolution of tourist services related to the filming of films (Ander, 1989). On the other hand, as a qualitative part, the interview was used (Hernández Sampieri, Fernández Collado, \& Baptista Lucio, 2003) so that those involved in these services could express their opinions on the subject. Likewise, a digital newspaper review was carried out (Ander, 1989) to know the advertising promotion of the regions using as an attribute the filming of the cinematographic productions in the area.
\end{abstract}

Spectre, Bandidas, Tourist commercial activities, Cinematographic productions and tourism

Citación: LÓPEZ-HERNÁNDEZ, Sonia, LÓPEZ-MARTÍNEZ, Ma. Teresa y ESQUIVEL, Rocío. Actividades comerciales turísticas luego de filmar Bandidas y Spectre. Revista Transdisciplinaria de Estudios Migratorios. 2019, 5-15: 15-25

\footnotetext{
* Correspondencia al Autor (correo electrónico: sonilh74@yahoo.com.mx)

$\uparrow$ Investigador contribuyendo como primer Autor.
} 


\section{Introducción}

La importancia del fomento del turismo y del desarrollo local a partir de la industria del cine, prestando especial atención al impacto económico local que generan las producciones cinematográficas en un espacio determinado, ha suscitado interés académico de investigación de casos como Grihault $(2003,2007)$, Tzanelli (2003,2006), Graml (2004), Beeton (2005), Jones and Smith (2005), Hudson and Ritchie (2006), Bolan and Crossan (2006) and Carl et al. (2007).

México es importante en la industria cinematográfica a nivel internacional ya que cuenta con una importante capacidad productora y creativa en la industria cinematográfica; y tiene escenarios variados y destrezas de productores, directores, artistas y técnicos acumuladas en años de experiencia (Martínez Piva,, Padilla , Schatan, \& Vega Montoya, 2010; Núñez, 2005). Entre las experiencias destacadas está la filmación de películas del género western en Durango, escenarios que hoy funciona como paseo temático se llaman Villas del Oeste y Chupaderos; dos pueblos de calles polvorientas donde abundan los vaqueros, las cantinas, los sheriffs y las bailarinas de cancán, que vieron pasar al legendario John Wayne.

Esto da cuenta de que en México el impacto económico local y fomento del turismo a partir de la industria del cine es un tema de interés, prestando especial atención en el desarrollo local posterior al rodaje de las producciones. Por esa razón, se considera necesario abordar casos particulares para insistir en la necesidad de una gestión y planificación de servicios turísticos relacionados al rodaje de un film. En consecuencia, el objetivo de esta comunicación es realizar una revisión de dos casos de locaciones de México en las que se filmaron Bandidas (2006) y Spectre (2015), y que aprovecharon de forma diferente el atractivo que representa figurar en una producción cinematográfica y muestran una planificación de servicios turísticos disímil.

Este trabajo es un acercamiento a lo que se presenta en la gestión y planificación de servicios turísticos en los escenarios de Zacatecas y la Ciudad de México en los que se rodaron Bandidas (2006) y Spectre (2015), respectivamente, a fin de aproximarnos de forma general al contexto.
Cabe destacar que un plan de marketing incluye análisis interno y externo, planes y estrategia, y no es la intensión de este texto establecer la ventaja competitiva. Este tipo de análisis permite esbozar los principales factores/atributos que tienen estas localidades respecto al rodaje de un film para su posterior consideración en la planificación turística. Para dicho fin, el siguiente texto presenta la metodología utilizada, el contexto general del cine como potencial para el turismo, los casos de Bandidas y Spectre, y las reflexiones finales.

\section{Metodología}

Los estudiosos de los medios tratan de encontrar regularidades en los efectos de los medios, más que evidencia anecdótica, por lo cual es pertinente particularizar acerca de lo que se pretende estudiar (el canal, el efecto inmediato o a largo plazo, etc.). La teoría de la bala mágica (del Fondo Payne) sostiene que el contenido de los medios tiene una relación causal directa con el comportamiento, pero actualmente los estudiosos creen que los medios producen efectos diversos sobre distintas personas.

De ahí la pertinencia de analizar sólo la conexión directa entre el mensaje de un film y las actividades del prestador de un servicio turístico basado en dicho contenido, con la intensión de establecer un impacto positivo en la afluencia turística.

En ese sentido, para establecer dicha relación la metodología adoptada fue una combinación de técnicas (Arias Alpízar, 2009) (Hernández Sampieri, Fernandez Collado, \& Baptista Lucio, 2003). La parte cuantitativa se valió de la caracterización la zona, revisión de los catálogos de servicios turísticos de las regiones, comparación histórica de la evolución de los servicios turísticos relacionados con la filmación de las películas (Ander, 1989). Por otra parte, como parte cualitativa, se utilizó la entrevista (Hernández Sampieri, Fernandez Collado, \& Baptista Lucio, 2003) para que los involucrados en estos servicios externaran sus valoraciones de la temática. Asimismo se realizó una revisión hemerográfica digital (Ander, 1989) para conocer la promoción publicitaria de las regiones utilizando como atributo la filmación de las producciones cinematográficas en la zona. 


\section{Contexto}

En la construcción de la realidad los medios de comunicación juegan un papel fundamental y en el que la negociación de esquemas no es dialéctica (Ramos, 1995). En particular el cine transmite ideas, valores y actitudes, y aunque su influencia es indudable "el modo y el grado en que ésta se produce está todavía abierto a debate" (Pardo, 2004). Varios autores coinciden en que el cine es "espejo y moldeador de mentalidades y comportamientos (...) las películas actúan como $<$ dramas de reafirmación» de las propias creencias, actitudes y valores" (Pardo, 2004).

En este contexto, cada producción cinematográfica se convierte en un "espacio donde se socializan los imaginarios que los turistas tienen con respecto de los destinos a partir de la información que se les presenta" (Novo E. de los Montero, 2012). Esto sin entrar en detalle de la discusión sobre si esa actuación de los medios es distorsionada o no (Vázquez Anderson, 2004). Como muestra de esto Rodríguez Campos y Fraiz Brea (s/a), quienes retoman a Hernández Ramírez (2004), reportan el ejemplo del largometraje Vacaciones en Roma (1953) "como un itinerario por los lugares más representativos de la ciudad funcionando como verdadera guía turística.

Otras veces, las localizaciones seleccionadas son el contexto de fantasías o relatos históricos. Aquí el cine construye una ilusión que puede incrementar el atractivo de los destinos. La película Buscando a Nemo (2003) es en este sentido sorprendente, pues el éxito de la cinta está suponiendo la multiplicación de las visitas a la Gran Barrera de Coral (Australia) que es Patrimonio de la Humanidad desde 1981." (Rodríguez Campos \& Fraiz Brea, pág. 3)

Alsina (1989) explica que un acontecimiento es aquello que sucede dentro de la realidad como resultado de la percepción que se tiene del sistema, es decir para que un acontecimiento sea tal cosa, los individuos deben hacer una interiorización cognitiva de él.

\footnotetext{
1 Algunos ejemplos son: Ayudas a las industrias culturales (España): programa de apoyo del MECD, orientado a incrementar la oferta legal de contenidos digitales culturales en Internet y a promover la modernización e innovación de las industrias culturales y creativas. El FICOD (España): foro internacional de contenidos digitales organizado a través de ISSN: 2414-4967

ECORFAN® Todos los derechos reservados
}

Lo anterior se basa en la premisa de que la realidad no está separada de la forma en que sus miembros la interpretan. Así disturbios y las revueltas en Egipto producto de la inestabilidad política en el 2011 y difundido en los medios de comunicación provocaron pérdidas en el turismo (La Jornada, 4 de febrero de 2011, p. 30). En ese momento de inestabilidad los atributos culturales y patrimonio del lugar o la imagen de exotismo de ese país pasaron temporalmente a segundo plano ante la información (los acontecimientos) presentada en los medios e interiorizada por los sujetos. (Novo E. de los Monteros, Osorio García, Torres Nafarrete, \& Esquivel Solís, 2012)

Así, la conformación de "una realidad" es pues un fenómeno social en que cual puede intervenir el cine con sus múltiples procesos publicidad, grabación, noticias,etc. para moldear la percepción del mundo y hacernos partícipes de su forma de entenderlo, aporta información, una construcción selectiva del conocimeinto de la sociedad, señalan lo importante y trival mediante lo que muestran y lo que ignoran (Ramos, 1995). Pocas personas pueden percibir el mundo y la sociedad a través de medios especializados o de la interacción directa con otros actores (Misas Arango, 2005).

Además, la producción cinematográfica, al igual que otros medios de comunicación, ha multiplicado las vías de explotación cinematográfica con diferentes proyectos públicos y privados de distribución de materiales (Ojer \& Capapé, 2012). Las herramientas digitales pueden constituir un claro aliado a la hora de fomentar la participación de la sociedad en civil y la sensibilización torno a la diversidad de las expresiones culturales, sólo en España e Hispanoamérica proliferaron proyectos $^{1}$ para facilitar la distribución internacional de las obras y consolidar el mercado cultural digital a nivel de toda la región (UNESCO, 2006).
Red.es por el Ministerio de Industria, Energía y Turismo. Constituye una de las herramientas de la Agenda Digital para España. Y el Emprendelibro (España): programa de asistencia a emprendimientos de edición digital, llevado adelante por la Fundación Germán Sánchez Ruipérez y Factoría Cultural, con el respaldo del MECD.

LÓPEZ-HERNÁNDEZ, Sonia, LÓPEZ-MARTÍNEZ, Ma. Teresa y ESQUIVEL, Rocío. Actividades comerciales turísticas luego de filmar Bandidas y Spectre. Revista Transdisciplinaria de Estudios Migratorios. 2019 
Asimismo, la tendencia del negocio en Estados Unidos, que se presume es la que seguirá el resto, apunta a que "las nuevas generaciones prefieren el consumo individualizado, especialmente a través de la interfaz de un móvil, un reproductor de vídeo, una tableta $\mathrm{u}$ ordenador, que les permite consumir los contenidos cuándo y dónde quieran". (Ojer \& Capapé, 2012, pág. 191)

Las empresas distribuidoras de contenidos audiovisuales a través de Internet han conseguido ofrecer un servicio que atiende la demanda del público actual. "También es destacable su fuente de ingresos, basada en suscripciones económicas no muy elevadas, asequibles para el público joven al que se dirigen(...) este nuevo modelo de negocio está en expansión, teniendo en cuenta que los usuarios de Internet en el mundo crecieron un $445 \%$ entre 2000 y 2010 y siguen aumentando" (Ojer \& Capapé, 2012, pág. 192).

De esta manera, la transmisión ideas, valores y actitudes de ciertos lugares y personas en los medios, el cine entre ellos, aumenta su valor como detonador de actividades comerciales para el turismo después de la filmación de un film y de su distribución.

El análisis de este proceso de promoción de un lugar mediante las producciones cinematográficas no es nuevo, la literatura es basta en el área: La imagen turística en el cine (Rofríguez Campos \& Fraiz Brea, 2012), Marketing internacional de lugares y destinos (Kotler, Gertner, Rein, \& Haider, 2007) e Imagen turística y medios de comunicación (Novo E. de los Monteros, Osorio García, Torres Nafarrete, \& Esquivel Solís, 2012), y muestra una mayor experiencia en países europeos, como: Turismo cinematográfico y desarrollo económico local. El festival de cine de Huelva (Flores Ruiz, 2015), El cine como inductor del turismo. La experiencia turística en Vicky, Cristina, Barcelona (Aertsen, 2011) y Consideraciones estratégicas para la promoción del turismo en Galicia a través del cine (Rodríguez Campo \& Fraiz Brea, 2010).

Los casos en México en los cuales se ha registrado y evidenciado un aumento de las actividades comerciales para el turismo tras una producción cinematográfica son escasos.
Novo E. de los Monteros (2012) menciona en su estudio dos películas mexicanas que ayudaron a posicionar a Puerto Vallarta y Cancún como destino de playa, La noche de la iguana (1964) y 10 La mujer perfecta (1979), respectivamente.

Pero en general, no existe una planeación para promover entre los habitantes de una comunidad receptora de este tipo de industria, propuestas culturales para que el turismo se fortalezca y la comunidad se involucre en esta actividad como una forma de vida, tal como observa en Real de Catorce en San Luis Potosí, México. (Alvarado Solís).

\section{Bandidas: Durango, San Luis Potosí, Zacatecas y la Ciudad de México}

En el caso del rodaje de la producción Bandidas (Roenning \& Sandberg, 2006), las locaciones según la Internet Database (IMDb) (Internet Movie Database, 2017) fueron: Durango utilizó como set el Museo Francisco Villa, la Plaza Cuarto Centenario y el desierto; San Luis Potosí con Real de Catorce como escenario, pueblo mágico desde el 2001; Zacatecas con la Sierra de Órganos y Sombrerete, pueblo mágico desde el 2012; la Ciudad de México con los estudios Churubusco y el Jardín Botánico de la UNAM.

En Durango una de las locaciones de mayor relevancia fue el actual Museo Francisco Villa, el cual no reporta datos relacionados con la llegada de visitantes tras la filmación, pues en el año en el que se rodó la película este lugar aún era el palacio de gobierno.

\section{Solís observó:}

Respecto a Real de Catorce Alvarado

"Cabe mencionar que la visita de Díaz a la zona se dio en 1895, aun cuando las fotografías mencionan el año de 1896. Estas imágenes inspiraron una puesta en escena en 2006, llamada Festival del Túnel de Ogarrio, para conmemorar la inauguración del túnel, en 1902. La participación de mucha gente del pueblo en ese evento puede apreciarse en una película que se presenta, durante la temporada de turismo, en la antigua plaza del Carbón, donde los habitantes visten indumentaria de la película Las Bandidas, filmada en esta localidad, dando pie a un evento para la mercadotecnia turística”. (Alvarado Solís, pág. 65) 
El festival se celebra el 2 de abril de cada año para conmemorar la inauguración del Túnel de Ogarrio; sin embargo, no hay promoción de este festival mismo. Por otra parte esta región presenta un crecimiento de llegada de 7,591 turistas desde el año en el que la película se estrenó hasta el año siguiente, la motivación de dicho incremento no se especifica en fuentes como la Secretaría de turismo (SECTUR) o el Sistema Nacional de Información Estadística del Sector Turismo de México (DATATUR), ni la oficinas de la Secretaría de Turismo en San Luis Potosí.

Sin embargo, de acuerdo al Compendio Estadístico del Turismo en México se observa un incremento en el número de guías turísticos en los estados involucrados en el siguiente año (SECTUR, 2016, pág. 10.4). (Gráfica 1). De forma complementaria la actividad hotelera en los destinos turísticos de Sobrerete o Real de Cartorse en esos años no se dispone de información. En el mismo rubro, actividad hotelera, los cuartos que se encuentran en servicio al mes de diciembre de cada año en Durango, Zacatecas y San Luis Potosí, presentan un incremento (Gráfica 2), pero no se puede establecer una relación directa con la filmación de las producciones cinematográficas.

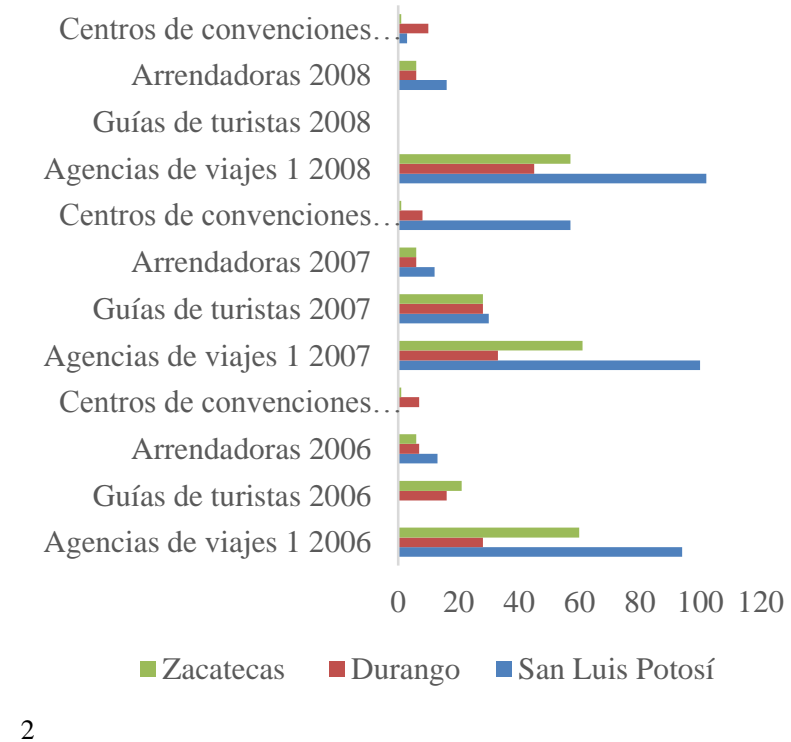

Gráfica 1 Oferta de otros servicios turísticos Fuente: SECTUR 2016

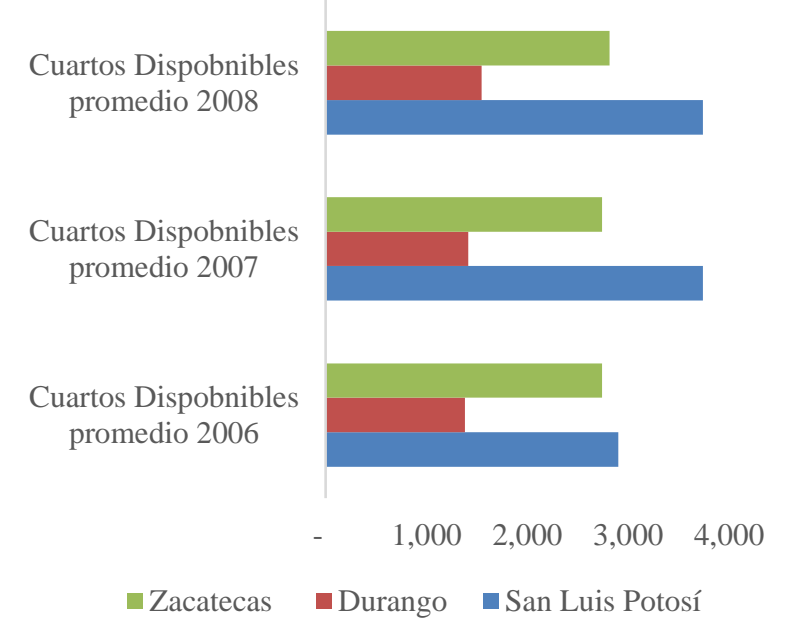

Gráfica 2 Cuartos que se encuentran en servicio al mes de diciembre de cada año

Fuente: SECTUR 2016

En entrevista telefónica, la guía especializada, Margarita Escamilla (Escamilla, 2017), de la Secretaría de Turismo, en Zacatecas explica que sus colegas utilizan en sus recorridos información sobre las películas que han sido rodadas en Sierra de Órganos, y que además cuentan con un museo municipal Villa de Llerena dónde se exhiben, las fotografías de los actores y actrices que han estado ahí para "Mostrar a todos los visitantes el material iconográfico, documental y museográfico que se ha acumulado a través del desarrollo histórico de la ciudad de Sombrerete." (México, s.f.)

\section{Spectre de la saga del agente 007 James Bond}

En el año 2015 la película Spectre (Mendes, 2015), de la saga del agente 007 James Bond, tuvo como locación al Zócalo capitalino de la Ciudad de México, donde el festival de día de muertos fungió como fondo principal para los primeros 4 minutos y 40 segundos de la película, y se aprecia al protagonista en medio de la celebración dirigiéndose a un hotel de la ciudad para luego salir por la ventana de una de las habitaciones y caminar por la azotea enmarcando la celebración, calles y algunos edificios del centro.

\footnotetext{
${ }^{2}$ En el rubro de Agencias de viajes se consideró el total que incluye mayoristas, minoristas, especializadas y Tours operadores porque en algunos estados no existe desglose del concepto.
}

ISSN: 2414-4967

ECORFAN® Todos los derechos reservados 
Según la ex titular de la Secretaría de Turismo (SECTUR) en el 2015, Claudia Ruiz Massieu, citada por el periódico Informador: "la filmación genera una importante derrama económica en el país, al producir miles de dólares diarios por la ocupación de habitaciones de hotel y consumo de alimentos por parte del equipo de producción, y más de dos mil 500 técnicos y creativos, artesanos y extras tienen un empleo gracias al rodaje." (Sin embargo, 2015) Pero a diferencia de lo anterior la revista Forbes México publicó que: "Durante el periodo vacacional de Semana Santa se espera la visita de medio millón de personas, sin embargo el cierre a la vialidad vehicular y peatonal por las grabaciones de la película del agente secreto ha puesto en jaque a los negocios aledaños, los cuales hasta la fecha han registrado pérdidas por 377 millones de pesos." (Meza Orozco, 2015)

Luego del estreno de la película el 2 de noviembre del 2015, el gran impacto que generó en el extranjero motivó un año después a las autoridades de la ciudad a realizar un festival que de manera tradicional no se hacía; así lo menciona la Revista Milenio quien cita a Lourdes Berho directora ejecutiva de la junta de turismo en México en el 2016: "Cuando esta película llegó a la pantalla grande y millones de millones de personas la vieron en la pantalla grande de 67 países, eso comenzó a crear la expectativa de que nosotros haríamos algo" dijo Berho, "sabíamos que esto iba a generar deseo de parte de la gente de aquí, entre mexicanos y turistas, para venir y participar en una celebración, un gran desfile" (Milenio, 2016)

El desfile se llevó acabo el 29 de octubre del 2016 en donde se exhibió parte de la utilería de la película y se promocionó en la página web México Desconocido con el siguiente anuncio:

\section{"Desfile de calaveras monumentales de Día de Muertos}

Este Día de Muertos la Ciudad de México se llenará de color, música y muy buen ambiente en un magno festival que se espera tenga todo el estilo de la película del agente "007". Cuándo: 29 de octubre.

Dónde: Partirá de la glorieta del Ángel de la Independencia y concluirá en la plancha del Zócalo." (México desconocido, 2016)
De lo anterior se puede inferir que esta película del agente secreto se intentó utilizar como atractivo para los turistas ya que de acuerdo con el secretario de Turismo de la ciudad en el 2016, Miguel Torruco: "se espera una derrama económica de 963 millones de pesos, y alrededor de 162 mil turistas, 32 mil de los cuales son extranjeros. Esta cifra se refiere a los turistas que se hospedarán en hoteles y habría que añadir a aquellos que se quedan en casas de familiares o que vienen a la ciudad por menos de 24 horas.” (La Jornada, 2016)

El recuento final fue "De acuerdo con la Secretaría de Turismo de la Ciudad de México, la derrama económica del monumental desfile fue de 52 millones de dólares, con una ocupación hotelera casi del 100\%" (CNN Español, 2016)

También se debe mencionar que en la página oficial de la película (solo en el idioma inglés si se cambia al español la página ya no muestra este apartado) reconoce la participación de México y la importancia que tuvo para la película por lo que decidieron realizar el estreno en la ciudad, como lo declaran lo productores: Producers Michael G. Wilson and Barbara Broccoli commented, "We owe our magnificent Day of the Dead opening sequence, shot in Mexico City, to the expert craftsmanship of our wonderful British and Mexican crews. With 2015 being the Year of Culture between the UK and Mexico, it is fitting that the Premiere of the Americas will take place in Mexico City, on the actual Day of the Dead Festival." (Spectre 007, s.f.)

Si bien en la publicación anterior no se promueve a México como destino turístico este reconocimiento permite que millones de seguidores de esta película volteen a ver al país, como anteriormente la citada Lourdes Berho nos menciona. Para el 2017 el festival se realizará de nuevo. En entrevista la productora Cristina King (King, 2017), directora General Festival Centro Histórico México, dice que "la productora Anime In participará en el desfile con el llamado carnaval de calaveras, mismo que se enfocará en lo más visible de nuestra fiesta de muertos de Spectre: calaveras, las imágenes de posada, altares y algún homenaje que creo tendrán en los carros alegóricos. 
El desfile tendrá 4 grandes carros alegóricos con escenas de lo que sucede alrededor, música en vivo, música grabada, una rola especial de México lindo y querido que está arreglando el gran Camilo Lara, del Instituto Mexicano del sonido." Y la participación de diferentes voluntarios "aquí si participa todo el mundo" dice.

Así, en definitiva la película Spectre fungió como un factor importante para la promoción turística, y en palabras de King además "este desfile en el futuro siga creciendo con una autoestima para las generaciones y los jóvenes y no tan jóvenes que digan tenemos que sostener la memoria histórica de dónde venimos".

De igual modo, en 2017 la Ciudad de México fue locación para la filmación de la nueva producción de "Godzilla: King of Monsters". El jefe de Gobierno capitalino, Miguel Ángel Mancera Espinosa, señaló que esta superproducción "nos reafirma como una locación importante a nivel mundial". Recordó que hace algunos años la capital mexicana estuvo presente en la filmación y producción de la película "James Bond", que ahora se habla de una superproducción. (fórmula, 2017)

De acuerdo con el jefe de gobierno de la Ciudad de México, México es el segundo mercado para la distribución de este cine. Y "sostuvo que al igual que Spectre, la vigésimo cuarta película de James Bond, que se filmó en esta capital, se tiene estimada (con Godzilla) una importante derrama económica que beneficiará a la Ciudad de México, además de se tiene confirmada la contratación de más de dos mil personas para enfrentar los retos de producción, a través de empleos directos e indirectos. (Excélsior, 2017)

Cabe señalar que en marzo de 2017 la capital del país recibió el reconocimiento Premios Excelencias Turísticas 2016 por posicionar a la marca CDMX como número uno entre los destinos de ciudad. El premio fue organizado por la empresa del ramo turístico y cultural, Grupo Excelencias, reconocida por la Organización de las Naciones Unidas para la Educación, la Ciencia y la Cultura (Unesco), explicó el Gobierno de la Ciudad de México en un comunicado (S/A, 2017).

\section{Reflexiones}

En un contexto donde los medios de comunicación juegan un papel fundamental en la construcción de la realidad, y en una era en la que el crecimiento de la difusión de materiales audiovisuales crece, el cine es un espacio idóneo para aumentar el valor de los lugares y locaciones utilizados en las producciones, ya que se relacionan con ideas construidas en el film, las cuales pueden ser positivas o negativas $y$ repercutir positivamente o negativamente en el lugar (Rodríguez Campos \& Fraiz Brea)

El rodaje de una película en una comunidad particular es "el momento en el que las autoridades turísticas pueden beneficiarse de que su destino sea incluido en un largometraje que será visto por millones de personas en todo el mundo, es decir, emplazar sus productos para generar imagen. Además, el sector audiovisual también sale beneficiado al recibir una contribución en especie (cortes de tráfico, alojamientos gratuitos, cesión de espacios públicos o personal, comidas, entre otras) y/o dineraria." (Rodríguez Campos \& Fraiz Brea, pág. 1)

Esto es una oportunidad para aumentar la afluencia de turistas a una región siempre y cuando se trabaje planificadamente en la identidad del lugar, el marketing del mismo y en las actividades comerciales ofertadas para el turismo, relacionadas con la filmación.

Para este último ítem, las actividades comerciales ofertadas para el turismo relacionadas con la filmación, es relevante para la comunidad sepa qué pueden esperar los turistas de visitar el lugar o satisfacer la experiencia del turista y justificar su viaje, lo que implica que toda la comunidad participe, conozca y se apropie. Es decir pensar en el cine como una oportunidad en turismo a largo plazo y no solo a corto plazo (Rodríguez Campos \& Fraiz Brea)

Así, en el contexto del cine como actuante en la construcción del imaginario de lugares y locaciones usadas en las producciones es necesario "conocer minuciosamente los deseos de los compradores, de manera que estén en condiciones de ofrecer el producto más conveniente" (Cárdenas Tabares, 2004, pág. 41). 
El destino turístico debe ser significativo y provechoso, recurrir a la historia, la cultura y su gente, este último es valor añadido si se trabaja con la hospitalidad, por ejemplo. (Kotler , García De Madariaga Miranda, Flores Zamora, Bowen, \& Makens, 2011)

La intención es crear una experiencia positiva del cliente, y en el caso del imaginario de la locación creado en la producción cinematográfica, considerada como una atracción del lugar no basta por sí misma para satisfacer al turista, sino que se debe buscar "dar un mayor significado al valor de la experiencia" a fin de evitar que haya un desajuste entre lo que espera recibir el cliente y lo que recibe lo que causa insatisfacción. (Kotler , García De Madariaga Miranda, Flores Zamora, Bowen, \& Makens, 2011)

Así, los prestadores de servicios deben orientar a los clientes en lo que están buscando del destino. Capacitarlos e integrarlos en los planes turísticos es parte de la planeación, y tratándose del uso de locaciones en el cine, los receptores del turismo deben apropiarse de las historias alrededor de las grabaciones o de los actores, por ejemplo.

En el caso analizado de las locaciones utilizadas para la producción de Bandidas se observa que el uso de escenarios y edificios en dicha película se concibe como atracción turística sólo en el museo municipal Villa de Llerena dónde se exhiben las fotografías de los actores y actrices que han estado ahí como parte de la historia reciente de la ciudad. Con lo que esas imágenes dejan constancia de su historia como algo único que no puede ser encontrado en otro lugar.

Así, el paisaje y los edificios que ya forma parte de la cultura de un pueblo se muestra como parte del imaginario colectivo mostrado en una película. El reto para lugares como en los que se filmó Bandidas es que estos atractivos dejen satisfechas las expectativas de los turistas en las diferentes formas de "consumo" que se pueden generar, y van desde sólo de visitar edificios hasta las historias y hospitalidad del destino.
Del lado opuesto, el caso de la Ciudad de México con la repetición del desfile y festival de Día de Muertos, como en la película 007: Spectre, pretende recrear la ilusión de la gran pantalla para que los turistas puedan participar de esta "realidad". Falta una evaluación empírica de la valoración de los turistas al respecto y de los prestadores de servicios alrededor del uso de la información y promocionales con el tema, y, evidentemente, de la formación de la imagen de la Ciudad de México como destino turístico a través del cine.

Sin embargo, es probable que repetir un festival como en una película no sea suficiente para una Ciudad de México, con una imagen "complicada" en las noticias y en las experiencias de los extranjeros o turistas que la visitan, incluso en algunos films [por ejemplo Amores Perros (González Iñárritu, 2000)]. Se debe tener presente que el cine participa de la conformación del imaginario sin una intensión comercial de atraer, es solo persuasión (Rodríguez Campos \& Fraiz Brea).

En conclusión, faltan propuestas que involucren a todos los participantes de un destino turístico para hacer realidad una experiencia fílmica favorable a los turistas; "los turistas desean reconocer, revivir con la mirada las imágenes que han sido anticipadas por la promoción turística, por encarnar éstas su anhelo de autenticidad" (Álvarez, 2006, pág. 7). Sin embargo, según Álvarez (2006) "esta dejadez se debe en parte a la ausencia de estudios profundos analizando los beneficios generados por esta actividad y las claves que permitan aprovecharla".

El reto está ahí, medios de comunicación proporcionan constante información actualizada a los consumidores, estimulando o no la práctica del turismo. Si el cine funciona como refuerzo y desarrolla símbolos que atraen diferentes grupos sociales es necesario identificar sus deseos y planificar su satisfacción si se quiere aprovecharlas como un atractivo del lugar.

\section{Referencias}

Aertsen, V. U. (agosto-noviembre de 2011). EL CINE COMO INDUCTOR DEL TURISMO. LA EXPERIENCIA TURÍSTICA EN VICKY, CRISTINA,. Razón y Palabra, 16(77).

Alsina, M. R. (1989). La construcción de la noticia. Barcelona: Ediciones Paidós.

LÓPEZ-HERNÁNDEZ, Sonia, LÓPEZ-MARTÍNEZ, Ma. Teresa y ESQUIVEL, Rocío. Actividades comerciales turísticas luego de filmar Bandidas y Spectre. Revista Transdisciplinaria de Estudios Migratorios. 2019 
Alvarado Solís, N. P. (s.f.). Lo que la fotografía dice a la etnografía. Alquimia.

Álvarez, C. (2006). Tras las Huellas del Celuloide. HostelTur, 6-20.

Arias Alpízar, L. (2009). Interdisciplinariedad y triangulación en Ciencias Sociales. Diálogos Revista Electrónica en Historia, 120-136.

Barrios Rubio, A. (2016). Narrativa periodistica en la convergencia de los medios. Estudios sobre el mensaje periodístico, 163-176.

Cárdenas Tabares, F. (2004). Mercadotecnia y productividad turística. México: Trillas.

CNN Español. (31 de octubre de 2016). CNN Español. Obtenido de CNN Español: http://cnnespanol.cnn.com/2016/10/31/mexicohonra-a-sus-muertos-con-un-desfile-basado-enla-cinta-spectre-de-james-bond/

\section{COMUNICACIÓN, I. T. (s.f.). IMAGEN TURÍSTICA Y MEDIOS DE COMUNICACIÓN.}

Echazarreta Soler, C. (1996). Comunicación audiovisual una didáctica interdisciplinar. Comunicar, 115-119.

Escamilla, M. (Febrero de 2017). guía especializada de la Secretaría de Turismo en Zacatecas. (H. Jonatan, Entrevistador)

Excélsior. (15 de agosto de 2017). Excélsior. Obtenido de Excélsior: http://www.excelsior.com.mx/funcion/2017/08/ $15 / 1181823$

Flores Ruiz, D. (2015). TURISMO CINEMATOGRÁFICO Y DESARROLLO ECONÓMICO LOCAL. EL FESTIVAL. Cuadernos de Turismo(36), 175-196.

fórmula, R. (15 de Agosto de 2017). Radio fórmula. Obtenido de Radio fórmula: http://www.radioformila.com.mx/notas.asp?Ide $\mathrm{n}=705870$ \&ideFC $=2017$

González Iñárritu, A. (Dirección). (2000). Amores Perros [Película].
Internet Movie Database. (27 de marzo de 2017). Internet Movie Database. Obtenido de Internet Movie

Database: http://www.imdb.com/find?ref_=nv_sr_fn\&q=b andidas\& $\mathrm{s}=\mathrm{all}$

King, C. (Agosto de 2017). Entrevista con la productora Cristina King, directora general del Festival Centro Histórico México. (J. Aragón, Entrevistador)

Kotler, P., García De Madariaga Miranda, J., Flores Zamora, J., Bowen, J., \& Makens, J. (2011). Marketing Turístico. Madrid: Pearson.

Kotler, P., Gertner, D., Rein, I., \& Haider, D. (2007). Marketing internacional de lugares y destinos. México: Pearson.

La Jornada. (20 de 0ctubre de 2016). La Jornada. Obtenido de La Jornada: http://www.jornada.unam.mx/ultimas/2016/10/ 20/mega-desfile-de-dia-de-muertos-el-29-deoctubre-en-la-cdmx

Marín Díaz, V. (2006). Medios de Comunicacion, educación y realidad. Comunicar, 192-197.

Martínez Piva,, J., Padilla , R., Schatan , C., \& Vega Montoya, V. (2010). La industria cinematográfica en México y su participación en la cadena global de valor. CEPAL.

Mendes, S. (Dirección). (2015). 007: Spectre [Película].

México desconocido. (Octubre de 2016). México Desconocido. Obtenido de México Desconocido:

https://www.mexicodesconocido.com.mx/event os-celebrar-dia-muertos-df-mexico.html

México, G. d. (s.f.). Sistema de información cultural. Obtenido de Sistema de información cultural:

http://sic.gob.mx/ficha.php?table=museo\&table _id $=774$

Meza Orozco, N. (31 de marzo de 2015). Forbes México. Obtenido de Forbes México: https://www.forbes.com.mx/james-bondamenaza-la-derrama-economica-de-semanasanta/ 
Milenio. (29 de Octubre de 2016). Milenio. Obtenido de Milenio: http://www.milenio.com/hey/dia_de_muertosprimer_desfile-spectre-james_bond-007-cdmxmilenio-hey_0_838116371.html

Misas Arango, G. (2005). La información en las sociedades contemporáneas. Revista de Economía Institucional, 137-163.

Novo E. de los Montero, G. (2012). IMAGEN TURÍSTICA Y MEDIOS DE COMUNICACIÓN. Estudios y Perspectivas en Turismo, 21, 1409 - 1432.

Novo E. de los Monteros, G., Osorio García, M., Torres Nafarrete, J., \& Esquivel Solís, E. (2012). Imagen turística y medios de comunicación. Estudios y perspectivas en turismo, 1409-1432.

Núñez, T. (2005). El cine ¿espejo de la realidad? Madrid: Ayto.

Ojer, T., \& Capapé, E. (2012). Nuevos modelos de Negocio en la distribución de contenidos Audiovisuales: el caso de Netflix. Revista Comunicación, 1(10), 187-200.

Pardo. (2004). El cine como medio de comunicación y la responsabilidad social del cineasta. En Codina, De la ética desprotegida (págs. 117-141). Navarra, España: Eunsa.

Ramírez, J. H. (2004). TURISMO INDUCIDO. LA CONFIGURACIÓN DE LA IMAGEN TURÍSTICA DE SEVILLA A TRAVÉS DEL CINE COMERCIAL. I Congreso Internacional Patrimonio, Desarrollo Rural y Turismo en el Siglo XXI-Osuna. Osuna.

Ramos, C. (1995). Los medios de comunicación, agentes constructores de lo real. Reflexiones, 108-112.

Rey, A. D. (2012). Cine y turismo:intersecciones polivalentes. Archivos de la Filmoteca(69), 1419.

Rodríguez Campo, M. L., \& Fraiz Brea, J. A. (2010). CONSIDERACIONES ESTRATÉGICAS PARA LA PROMOCIÓN DEL TURISMO EN GALICIA A TRAVÉS DEL CINE. Revista Galega de Economía, 19(2), 1-11.
Rodríguez Campos, M. L., \& Fraiz Brea, J. A. (s.f.). La imágen turística en el cine. Evaluación del imacto de un largometraje en la imagen percibida del destinoen que se emplaza. Vigo.

Roenning, J., \& Sandberg, E. (Dirección). (2006). Bandidas [Película].

Rofríguez Campos, M., \& Fraiz Brea, J. A. (2012). La imagen turística en el cine.

S/A. (20 de marzo de 2017). Ciudad de México recibe el reconocimiento Premios Excelencias Turísticas. Enfoque noticias, págs. $\mathrm{http} / / / \mathrm{www}$.enfoquenoticias.com.mx/noticias/ci udad-de-m-xico-recibe-el-reconocimientopremios-excelencias-tur-sticas.

Sánchez Martínez, M. (2000). La comunicación de masas y las otras comunicaciones. Paradojas y Análisis. Comunicar, 13-23.

Secretaría de turismo del Estado de San Luis Potos. (2007). Secretaría de turismo del Estado de San Luis Potosí. Comportamiento del sector turístico 2006. Obtenido de Secretaría de turismo del Estado de San Luis Potosí. Comportamiento del sector turístico 2006: http://www.turismoslp.com.mx/documentos/dE stadisticas/Comportamiento\%202007.pdf

Secretaría de turismo del Estado de San LuisPotosí. (2006). Secretaría de turismo del Estado de San Luis Potosí. Comportamiento del sector turístico 2006. Obtenido de Secretaría de turismo del Estado de San Luis Potosí. Comportamiento del sector turístico 2006: http://turismoslp.com.mx/documentos/dEstadist icas/comportamiento_turismo_2006.pdf

SECTUR. (2016). Compendio Estadístico del Turismo en México 2016. México: SECTUR. Obtenido de http://www.datatur.sectur.gob.mx/SitePages/Co mpendioEstadistico.aspx

Sin embargo. (2015). Sin embargo. Obtenido de Sin embargo: http://www.sinembargo.mx/1903-2015/1287122

Spectre 007. (s.f.). Spectre 007. Obtenido de Spectre 007: http://www.007.com/spectre/mexico-city-tohost-spectre-premiere-of-the-americas/ 
UNESCO. (2006). Informe El impacto de las tecnologías digitales en la diversidad de las expresiones culturales de España $e$ Hispanoamérica. Obtenido de El impacto de las tecnologías digitales en la diversidad de las expresiones culturales de España e hipanoamerica:

http://en.unesco.org/creativity/sites/creativity/fil es/sessions/10igc_inf4_the_impact_of_digital_t echnologies_octavio_kulesz_sp.pdf

Vázquez Anderson, A. (2004). Más allá de Habermas, la realidad de los medios de comunicación. Comunicación y Sociedad, 247273.

VIVES, M. (12 de septiembre de 2013). TURISMO INDUCIDO POR EL CINE :APLICACIÓN DEL CASO A LA CIUDAD DE BARCELONA. TURISMO INDUCIDO POR EL CINE :APLICACIÓN DEL CASO A LA CIUDAD DE BARCELONA. España. 